\title{
Letramento, Desejo e Prática no Contexto do Ciclo de Alfabetização: a Atuação do Programa de Formação Continuada (PNAIC) em Goiás
}

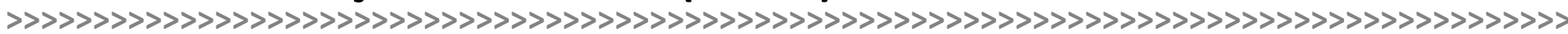

Myriam Marques*

\section{Resumo:}

Este estudo busca investigar como vem sendo desenvolvido o processo de domínio da leitura e da escrita no ciclo de Alfabetização proposto na Lei 11.274, de 06/02/2006, que altera os artigos 32 e 87 da LDB, Lei no 9.394 de 20/12/1996, instituindo a ampliação do ensino fundamental para nove anos de duração. Propõe uma reflexão sobre a compreensão dos processos de alfabetização e letramento, e contempla o Curso de Formação para Professores Alfabetizadores denominado PNAIC (Programa Nacional pela Alfabetização na Idade Certa) em Goiás. Aborda ainda a intencionalidade do mesmo quanto à consolidação da prática da leitura e escrita dentro do prazo que se estabeleceu para que todas as crianças possam estar alfabetizadas. Aborda também a atuação desejosa e comprometida dos professores para que estes possam atribuir significado e autonomia no processo de assimilação de diferentes saberes minimizando a problemática que se percebe quanto ao fracasso escolar.

\section{Palavras-chave:}

Alfabetização. Letramento. Desejo. Prática docente.

\begin{abstract}
:
This study aims to investigate how has been developed the process of reading and writing in the field Literacy cycle proposed by Law 11.274 of 06/02/2006, amending Articles 32 and 87 of the LDB, Law No. 9394 of 20/12/1996 establishing the extension of primary education to nine years in duration. It proposes a reflection on the understanding of literacy processes and literacy, and includes the Training Course for Literacy Teachers called PNAIC (for Literacy National Program on Certain Age) in Goiás. It addresses also the intention of the same as the reading practice of consolidation and writing within the time limit that was established so that all children can be literate. also addresses the willing and committed performance of teachers so that they can give meaning and autonomy in the process of assimilation of different knowledge minimizing the problem that is perceived as school failure
\end{abstract}

\section{Keywords:}

Literacy. Literacy. Desire. Teaching practice.

\section{Introdução}

As simples habilidades de identificar letras e conhecer números não conferem ao sujeito a prerrogativa de um individuo letrado. De acordo com a Pesquisa Nacional por

\footnotetext{
* > Graduada em Letras pela UEG (Universidade Estadual de Goiás). Especialista em Planejamento Educacional e Literatura Brasileira pela UNIVERSO. Especialista em Alfabetização e Letramento(UFG). Professora de Língua Portuguesa, Literatura Brasileira na Faculdade Católica de Anápolis. Professora no Curso: GOIÁS ENEM da Secretaria Estadual de Educação, Cultura e Esporte de Anápolis. Coordenadora Regional do PNAIC (Programa Nacional pela Alfabetização na Idade Certa) Regional Anápolis. E-mail: myriam.marques@seduc.go.gov. br
} 
Amostra de Domicílio (PNAD), realizada pelo IBGE em 2014, o percentual de pessoa analfabetas no Brasil é de 8,3\%. Segundo os dados do Relatório de Observação nº 5 sobre "As desigualdades na escolarização no Brasil" (BRASIL 2014), tais questões são atribuídas a problemas sociais, econômicos e culturais que se observam em quase todas as regiões do nosso país. Os dados constados deste relatório revelam um triste quadro apontando o índice de 13.105 milhões de pessoas analfabetas em 2014.

Ressalta-se que tais pessoas compõem um grupo de indivíduos que embora tenhan frequentado a escola, não se apropriaram de modo eficaz do processo de alfabetização e do letramento. Um número grande de crianças e jovens ocupam o espaço escolar, são assíduos em sala de aula, porém, não aprenderam a ler, escrever e tampouco interpretar.O presente Relatório traz ainda que, das crianças de 6 a 9 anos que frequentaram a escol em 2005 e em 2009, 25.9\% e 22.3\%, respectivamente, não sabiam ler e escrever. Estes números, acoplados à ausência de outras políticas para a educação, formatam o triste cenário que se observa no país.

Vale ressaltar que tentativas tem sido feitas no sentido de minimizar o problema. A implantação do Ensino Fundamental de nove anos é um exemplo disto. Tal medid propõe uma série de mudanças administrativas, de estrutura das escolas, pedagógicas e financeiras para que esta etapa da educação básica tenha êxito.

De acordo com o documento "Elementos Conceituais e Metodológicos para Definição dos Direitos de Aprendizagem e Desenvolvimento do Ciclo de alfabetização ( 1 $2^{\circ}$ e $3^{\circ}$ anos) do Ensino Fundamental" desenvolvido pelo MEC/2012, a criança tem, no início do Ciclo da Alfabetização, o direito de aprender a ler e a escrever em situações com a mediação do professor e em situacões mais autônomas, para que possa, no fina do Ciclo, chegar ao ler para aprender e escrever para seguir a escolarização

No entanto, a prática do ensino da leitura e da escrita sempre foi um grande desafio para os educadores, professores alfabetizadores, agentes públicos ligados à área da educação e, principalmente para as crianças em processo de assimilação do saber e domínio cognitivo da linguagem.

Vale ressaltar que as Diretrizes Curriculares Nacionais do Ensino Fundamental de Nove Anos, aprovadas em 2010, destinam esta responsabilidade ao Ministério da Educação em seu Artigo 49.

Segundo o texto do documento Elementos Conceituais e Metodológicos par Definição dos Direitos de Aprendizagem e Desenvolvimento do Ciclo de alfabetização $\left(1^{\mathrm{o}}, 2^{\mathrm{o}}\right.$ e $3^{\mathrm{o}}$ anos) do Ensino Fundamental desenvolvido pelo MEC/2012

Os resultados das pesquisas universitárias, os dados censitários nacionais, os diag nósticos dos exames avaliativos revelam uma evolução esperançosa, mas sem muita nergia com as urgências de atendimento aos direitos que têm geracōes de criançş, jovens e adultos que ainda serão excluídas nas próximas décadas (BRASIL, 2012).

Deste conjunto de resultados desanimadores, nasce o Pacto Nacional pela Alfabetização na Idade Certa, em novembro de 2012 com a assinatura de adesão de 5240 municípios e dos 27 estados da federação.

O Programa prevê ações governamentais de cursos sistemáticos de Formação de professores alfabetizadores, oferecidos pelas Universidades Públicas participantes da Rede de Formação, a disponibilização de materiais pedagógicos fornecidos pelo MEC prevendo registros e análise de resultados que induzem ao atendimento mais eficaz aos alunos em seu percurso de aprendizagem.

O documento que respalda o Pacto Nacional pela Alfabetização na Idade Certa, tecido a muitas mãos e "mentes pensantes" que compõem a Rede Nacional de Formação do MEC foi dividido em duas partes que englobam os Fundamentos Gerais do Ciclo de
Alfabetização, bem como os Direitos e Objetivos de Aprendizagem e Desenvolvimento por Área de Conhecimento e Componente Curricular de Língua Portuguesa que propõe prevê a aprendizagem das crianças entre 6 a 8 anos.

Nosso desejo nesta análise é verificar como se deu a implantaç̃o do Pacto Nacional na Rede Pública do Estado de Goiás, observando, justamente se o que consta do documento supracitado foi posto em prática no contexto das Secretarias Municipais e, consequentemente trabalhados nas salas de aula em nível das series iniciais, ressaltando que todos os atores envolvidos no processo de construção e efetivação do ensino-aprendizagem devem estar atentos para a real e eficaz aplicabilidade dos métodos e instrumentos posto em prática na sala de aula que garantam o progresso e o desenvolvimento de cada individualmente, estimulando-o à compreensão do mundo letrado.

No intuito de subsidiar a discussão, apresenta-se a seguir o resumo dos principais elementos que permeiam e formatam as ideias e proposituras apresentadas no documento referendado.

\section{A ampliação do ensino fundamental para nove anos}

A ampliação do Ensino Fundamental para nove anos desperta análises e reflexões que estimulam a problematização do contexto historico atual para que possamos trilhar novos rumos, pensando de modo diferente sobre a educação básica no momento presente. Assim sendo, torna-se necessário e contínuo o estudo dos aspectos práticos e legais que perpassam a implantação desta mudança no bojo das políticas públicas para a educação. Neste interim, faz-se mister buscarmos compreender os fundamentos que as sustentam numa abordagem psicossocial, ideológica, política e cultural, para assim, registrarmos nossa contribuição ao tema.

A priori, cabe ressaltar que, ainda que os documentos tragam orientações gerais sobre o percurso a ser seguido, alguns pontos deveriam ter sido apontados coletivamente no interior das escolas e demais instâncias do sistema educacional antes da implementação da proposta, haja vista que nosso interesse neste artigo é o reconhecimento de que ao mesmo tempo em que, a ampliação do Ensino Fundamental para nove anos é reconhecida como uma ação importante para a democratização do acesso à educação no país, a mesma suscita discussões com relação à efetiva alfabetização das crianças, posto que o ingresso da criança aos seis anos no ensino obrigatório tem sido considerado um meio de antecipar o ensino da leitura e da escrita.

A despeito deste assunto Furghestti et al. (2012, p. 89), realçam a relevância de que a ampliação do ensino fundamental para nove anos no Brasil se assemelha à prática de vários países que apresentam em média 12 anos de escolarização básica, incluindo países da América Latina e desse modo, visa equiparar-se aos demais países, no intuito de melhorar a política educacional, haja vista que, historicamente a educação brasileira enfrenta problemas ainda não superados: analfabetismo, altas taxas de evasão e repetência; má formação profissional, carreira e valorização de professores; infraestrutura inadequada entre outros.

Emerge daí a existência notória que se detecta no interior do sistema básico de ensino: a recorrente dualidade entre "acesso e sucesso escolar" (FURGHESTTI et al., 2012, p. 94), já que, o simples ingresso das crianças nas escolas brasileiras não tem significado a real apropriação do processo de alfabetização. Neste caso esta problemática representa um dos graves impasses á efetivação da qualidade na educação.

Por outro lado, Arelaro et al. (2011, p. 16), apontam-nos que o argumento predominante nas justificativas do Ministério da Educação (MEC) e na documentação legis- 
lativa sobre o ensino fundamental de nove anos é que a medida garante a ampliação do direito à educação para as crianças de 6 anos de idade, em especial as pobres e excluída do sistema educacional.

O que se levou em conta, segundo os autores supracitados, no momento da elaboração do texto legal, é que as crianças de 6 anos das classes média e alta pressupõe estarem já matriculadas em escolas, o que despertaria a necessidade de incluir, neste contexto as crianças pertencentes às classes menos favorecidas.

Desta propositura restou a confirmação de que as crianças de 6 anos ainda estavam fora da escola, seja pela não obrigatoriedade ou por não existir oferta de vagas suficientes na educação infantil pública. Tudo isso gerou a ideia de que o ensino fundamental de nove anos possibilitaria um maior número de alunos matriculados nas escolas brasileira e, portanto, assegurando a essas crianças o direito à educação.

No bojo do documento intitulado: Ensino Fundamental de Nove anos; Orientações para a Inclusão da Criança de Seis anos de Idade, Corsino (2007) analisa essa questão de modo reflexivo ao apresentar o ensino fundamental de nove anos como uma oportunidade histórica para as crianças de 6 anos das classes populares frequentarem a escola:

[...] a ampliação do ensino fundamental para nove anos, que significa bem mais que a garantia de mais um ano de escolaridade obrigatória, é uma oportunidade histórica de a criança de seis anos pertencente às classes populares ser introduzic a conhecimentos que foram fruto de um processo sócio-histórico de construção coletiva (CORSINO, 2007, p. 61-62).

\section{As alterações quanto à ampliação do ensino fundamental}

Vale ressaltar que a primeira parte do documento "Elementos Conceituais e Metodológicos para Definicão dos Direitos de Aprendizagem e Desenvolvimento do Ciclo de Alfabetização ( $1^{\circ}, 2^{\circ}$ e $3^{\circ}$ anos)" aborda o contexto atual do movimento curricular no ensino fundamental bem como trabalha o conceito de aprendizagem como direito humano. Perpassa ainda a conceituação de infância como elemento singular dessa aprendizagem, tendo o currículo e o ciclo contínuo de aprendizagens como viabilização desses direitos.

Já na segunda parte, são trabalhadas cada área de conhecimento e o componente curricular de língua portuguesa definindo os direitos de aprendizagens, os eixos que estruturam esses direitos e os diversos objetivos de aprendizagem de cada eixo, num rol que compõe cerca de 30 direitos, 20 eixos estruturantes e 256 objetivos de aprendizagem.

Vale ressaltar que a sistematização destes documentos, bem como todo o respaldo legal que fortalece e subsidia tais mudanças devem vir seguido de um fortalecimento e compreensão de todos os atores envolvidos no processo, como já foi mencionado anteriormente. A questão crucial e importante é sabermos como tais orientações e textos legais estão sendo trabah hados no interior da prática pedagógica, de forma que tais medidas não se tornem "letras mortas".

O próprio parecer CNE/CEB no 4 , aprovado em 20/02/2008, orienta sobre os três anos iniciais do ensino fundamental de nove anos, com ingresso aos seis anos de idade. Através deste documento o $\mathrm{CNE} / \mathrm{CEB}$ busca sanar dúvidas quanto ao tratamento pedagógico/metodológico destinado às crianças que frequentam os três anos iniciais do ensino fundamental.

São prerrogativas do referido documento:
Reafirmar a criação de um novo ensino fundamental com matrícula obrigatória aos seis anos a ser adotado por todos os sistemas de ensino até o ano de 2010;

Estabelecer o "ciclo da infância" com três anos de duração, sendo o $1^{\circ}$ ano parte integrante do mesmo, ratificando que este é um período dedicado à alfabetização e ao letramento, ao desenvolvimento das diversas expressẽes e ao aprentizdo das áreas de conhecimento (CNE/CEB nº 4, 2008).

Em uma nova análise, a aprovação da Resolução $\mathrm{CNE} / \mathrm{CBE} \mathrm{n}^{\circ}$ 7, aprovada em 4/12/2010, foram ratificadas as orientações sobre o ensino fundamental de nove anos nas séries iniciais. Dando ênfase ao ciclo alfabetizador, esta Resolução define em seu artigo 30 (BRASIL, 2010): "Os três anos iniciais do Ensino Fundamental devem assegurar: I - a alfabetização e o letramento [...]"

À luz destes princípios legais o governo institucionaliza o ensino fundamental como direito público subjetivo, estabelecendo a entrada das crianças de seis anos de idade no ensino obrigatório e, define os objetivos da ampliação do ensino fundamental para nove nos de duração visando

Melhorar as condições de equidade e de qualidade da Educação Básica; Estruturar um novo ensino fundamental para que as crianç̧as prossigam nos estudos, alcançando maior nível de escolaridade; Assegurar que, ingressando mais cedo no sistema de ensino, as crianças tenham mistempo mais lon zação e do letramento (BRASIL, 2009, p. 3 ).

Não obstante, questionamos: proporcionar mais tempo de escolaridade às crianças é suficiente para melhorar a qualidade da educação possibilitando a todos, o domínio eficaz da alfabetização seguido da habilidade de letramento?

Servimo-nos deste questionamento para tentarmos traçar um panorama da realidade atual quanto a real eficácia destas medidas na prática e suas contribuições para o alcance dos objetivos propostos na lei em questão. Soares (2003) é quem nos apresenta os conceitos de alfabetização e letramento, contribuindo para uma melhor assimilação destes pressupostos necessarios à inserção dos alunos ao universo cognitivo.

\section{Letramento e alfabetização, um processo integrado}

No bojo das proposituras de Magna Soares sobre o processo de construção da escrita e da leitura encontra-se a distinção entre alfabetização e letramento. Soares (2003) indica-nos que foi na década de 90 , que o conceito de alfabetização passou a ser analisado à luz do conceito de letramento, suscitando inúmeras pesquisas sobre essa correlação.

É oportuno lembrar que Letramento é uma palavra que tem origem na tradução da versão em inglês literacy, para o português, onde letra vem do latim littera, e o $c y$ denota qualidade, condição ou estado. Portanto, literacy é a condição de ser letrado (SOARES, 1998, p. 61). Agrega-se a esta definição a ideia de que a escrita traz consequências sociais culturais, politicas, econômicas, cognitivas, linguísticas, quer para o grupo social em que

Neste cenário, reconheça-se que o processo de alfabetização na perspectiva crítica só poderá ser mediado por um professor-cidadão letrado, consciente de sua função e conhecedor sobre a complexidade do tema alfabetizar - letrando.

No entanto, a ideia de emparelhar tais conceitos provoca em Soares (2003, p. 85), ma importante reflexão posto que, embora alfabetização e letramento sejam conceitos frequentemente confundidos e sobrepostos, a autora afirma ser importante distingui-los, 
ao mesmo tempo contrapô-los, visto que tal confronto faz-se necessário porque a introdução, no campo da educacão, do conceito de letramento tem ameaçado perigosamente a especificidade do processo de alfabetização.

Em contrapartida, afirma a autora, a aproximação é necessária porque não só o processo de alfabetização altera-se e reconfigura-se no quadro do conceito de letramento, como também este é dependente daquele.

Contudo, na análise apontada por Soares (2003, p. 94), um ponto merece destaque e refere-se ao fato de que tem havido um certo distanciamento do foco no complexo processo da alfabetização, onde vem sendo estabelecido um exaustivo uso das práticas de letramento de modo aleatório e ineficiente.

Portanto, é neste modo aleatório e desconexo de trabalho com foco no letramento, que pode estar havendo perda de funcionalidade na prática do processo de alfabetizar proposto pelo PNAIC, enfatizando que a prática de alfabetizar não pode e nem deve perder seu caráter eficaz. Dessa forma, alfabetizar abarca dimensões fundamentais, onde um ponto crucial deve estar associado às bases da Prática de Alfabetização na perspectiva do Letramento: o desejo de ensinar.

Soares aponta-nos os conceitos de modo bem claro:

"Se alfabetizar significa orientar a própria criança para o domínio da tecnologia escrita, letrar significa levá-la ao exercício das práticas sociais de leitura e escrit ". Uma criança alfabetizada é uma criança que sabe ler e escrever, uma criança letrad [...] é uma criança que tem o habito, as habilidades e até mesmo o prazer da leitura da escrita de diferentes genneros de textos, em diferentes suportes ou portadores, en diferentes contextos e circunstâncias [...]" (JORNAL DO BRASIL, 2000).

Vale ressaltar, no entanto, que todo esse mecanismo de desenvolvimento cognitivo deve estar associado ao estímulo, à motivação e o desejo de aprender. Neste complexo movimento entre a prática e a teoria, não nos esqueçamos do impulso necessário à toda aprendizagem: o desejo.

Desejo este que deve estar presente como mola propulsora, latente no interior dos sujeitos que compõem o processo de aprendizagem. Depreende-se daí que o professor deve ser um conhecedor desejoso do processo que permeia a construção subjetiva do domínio da linguagem reconhecendo que, por meio de uma prática metodológica consciente, poderá garantir à eficácia de formar cidadãos letrados. Ressalta-se, neste contexto, que as Estratégias de Ensino da Língua que permitam alfabetizar e letrar ao mesmo tempo devem perpassar basicamente pela Oralidade, Leitura, Escrita e a Análise Linguística.

Pensando nisso, entende-se a partir da afirmativa de Soares (2010, p. 33) que há uma diferença entre saber ler e escrever, ser alfabetizado, e viver na condição ou estado de quem sabe ler e escrever, ser letrado.

[... a pessoa que aprende a ler e a escrever - que se torna alfabetizada - e que pass a fazer uso da leitura e da escrita, a envolver-se nas práticas sociais de leitura e de escrita - que se torna letrada - é diferente de uma pessoa que não sabe ler e escrever é analfabeta - ou, sabendo ler e escrever, não faz uso da leitura e da escrita alfabetizada, mas não é letrada, não vive no estado ou condição de quem sabe ler escrever e pratica a leitura e a escrita (SOARES, 2010, p. 36).

Diante do exposto, cabe-nos ressaltar que várias e constantes ações/programas ven sendo implementados pelo Estado brasileiro para que as crianças do ciclo de alfabetização possam ser alfabetizadas e letradas, assegurando o que determina a legislação nacional.
Neste constante emergir de Programas e ações implementadas, faz-se necessário vançarmos para além do simples acesso da criança ao ambiente escola. Assim, é fundamental que os alunos permaneçam nas escolas, se apropriem dos saberes, se alfabetizem e, que estes conhecimentos permitam melhorar a qualidade de vida destas crianças e da comunidade familiar. Afinal, o principio fundamental da escola é preparar os alunos para a vida e a sociedade. Neste caso enfatizamos a profícua importância da alfabetização com letramento na escolarização.

Ressalta-se, a guisa do termo alfabetização, que este é compreendido como o processo de apropriação do sistema de escrita de uma língua. De acordo com Soares (2011, p. 15) "[...] alfabetização em seu sentido próprio, específico: processo de aquisição do código escrito, das habilidades de leitura e escrita." Nesse sentido, a alfabetização é a aprendizagem da codificação e decodificação dos sinais gráficos.

Com a antecipação, o Estado busca universalizar esta etapa da educação básica, possibilitando às crianças, antes sem acesso a pré-escola, agora ingressar e frequentar o $1^{\underline{0}}$ ano, como também, promover aprendizagem principalmente com ênfase no ciclo da alfabetização.

Destacamos que crianças que tem a oportunidade de estar na escola em um tempo maior, se socializam melhor com outras crianças, criam mais oportunidades de brincar e inserir-se num contexto cultural novo, ampliando, desta forma, suas possibilidades de aprendizagem. Esta ampliação, se efetivada a contento, priorizando o processo de alfabetização com letramento poderá promover ainda, melhores condições às crianças para dar continuidade aos seus estudo

\section{A formação continuada dos professores alfabetizadores}

Notadamente, as proposituras inerentes ao processo de alfabetização, estabelecem relação íntima com formação e a prática do professor que tem papel primordial no processo, requerendo domínio teórico-prático dos elementos que compõem a complexa teia do ensinar e do aprender.

No entanto, a frequência com que ouvimos recorrentes críticas e reclamações dos professores quanto a não participação da família bem como o não acompanhamento dos estudos de seus filhos em casa, leva-nos a um inevitável questionamento: quando a família falha, a escola deve abster-se de tentar efetuar seu trabalho junto ao possível desenvolvimento dessas crianças?

Sabemos que a família e a escola têm funções específicas em relação à educação dos indivíduos. No entanto, tais funções, embora específicas em cada contexto, devem se interagir num "todo" que ajude a construir e a promover a formação básica destes sujeitos. De tal modo, urge o desafio de conscientizar os professores e demais agentes educativos, que devemos atuar como os parceiros mais experientes, aqueles que, pressupõe-se estarem preparados para analisar e oferecer diferentes formas de fazer chegar o conhecimento e .

Neste complexo universo, a formação continuada dos professores deve contribuir para que a profissão docente tenha domínio teórico-prático para superar e ou minimizar as fragilidades que se detectam no interior das relações que se operam entre família e escola, ensino e aprendizagem.

O PNAIC - que trata de uma formação especifica para professores alfabetizadores - surgiu como um importante estímulo aos professores e orientadores de estudo, que veem a possibilidade da realização de um trabalho melhor direcionado, respaldado por dire- 
trizes bem elaboradas, direitos de aprendizagem bem definidos, eixos estruturantes para o ensino das diferentes disciplinas, com foco no desenvolvimento da área da linguagen.

A criança neste contexto, tem, no início do Ciclo da Alfabetização, o direto de "aprender a ler e a escrever", em situações com a mediação do professor e em situações mais autônomas, para que possa, no final do Ciclo, chegar ao "ler para aprender" e "escrever para seguir a escolarização", o que significa uma evolução necessária, como estudante e cidadâ.

Dessa forma crê-se que as novas diretrizes que permeiam o PNAIC possam contrbuir para o atendimento de um número maior de crianças que entram na escola aos seis anos de idade, visando alfabetizá-las em um contexto de letramento. Assim, o papel propostos pelo referido Programa.

\section{O papel do professor como promotor da aprendizagem}

Sob o prisma do conteúdo proposto no material do Pacto Nacional pela Alfabetização na Idade Certa, Ano 1, Unidade 8 (BRASIL, 2012), que trata da Organização do Trabalho Docente para Promoção da Aprendizagem, percebe-se que "[...] a construção dos conhecimentos dos alunos não acontece em apenas uma intervenção". Assim, faz-se necessário proporcionar outros momentos que possibilitem aos nossos alunos novas reflexões sobre a mesma temática.

Daí vale reiterar que a formatação de um tecido profissional também é enfatizada no documento/material de formação do PNAIC, onde o papel do professor alfabetizador é fortalecer práticas cotidianas voltadas para a leitura de diferentes gêneros para que, através da recorrência de leituras diversas, o aluno possa assimilar verdadeiramente os conteúdos e as finalidades de cada texto.

Visando atender aos objetivos e especificidades do ensino da língua bem como a importância do trabalho do professor alfabetizador reiteramos a necessidade de que haja por parte deste profissional o desejo de FAZER, incluindo em sua prática a ênfase em atividades que envolvam o prazer e o gosto pela leitura, abrangendo a interação do próprio meio com diferentes textos literários, atividades em que as crianças possam conversar sobre o que leram, comparar textos com a realidade, levantar hipóteses, questionar serem questionadas, observar, experimentar e buscar a compreensão prática do que foi lido ou falado.

É oportuno lembrar que, associado a tais atividades de cárter experimental, o material propõe atividades que provoquem reflexões constantes sobre o funcionamento e a estrutura da língua escrita, tal qual sugere Ferreiro (1985, p. 52), em consonância com atividades que desenvolvam a consciência fonológica, a oralidade e atividades onde as crianças possam escrever espontaneamente, testando suas hipóteses psicogenéticas da escrita.

Não obstante, recomenda-se aos professores alfabetizadores adotarem uma rotin sistemática na qual oportuniza as crianças refletirem sobre o sistema de escrita alfabética e sobre as práticas de leitura e escrita que circulam socialmente. Tal processo deve estar pautado em sequências didáticas e ou atividades experimentais que provoquem a construção e a apropriação de conteúdos específicos sobre a linguagem escrita.

\section{O Desejo de Ensinar}

O ato de ensinar é compreendido como um processo que consiste na transmissão de um dado conhecimento. Transmissão que se dá na interação de um sujeito que toma para si a função de ensinar a um outro sujeito, o aprendiz. Tal conhecimento,pode ser definido segundo Pain (1991, p. 80), como "[...] a organização operatória de um código, isto é, as regras pelas quais se pode gerar significado".

De acordo com Almeida (1993), o conhecimento constitui, portanto, os conteúdos concretos e mais variados que serão transmitidos na relação ensino-aprendizagem. É através desta relação que o aprendiz, usando uma série de estruturas cognitivas, e mobilizando afetos e desejo, se apropriará do conteúdo ensinado, transformando-o e sendo capaz de reproduzí-lo enquanto conhecimento elaborado.

O ponto básico a ser enfatizado sugere que no espaço vago entre o "ser" que ensina e o "ser" que aprende, more o desejo como possibilidade de que a aprendizagem ocorra. Neste cenário tem-se como ponto fundamental, que todos os alunos sejam alfabetizados na idade certa. Tal prerrogativa apresenta-se pelo menos, como um desafio a ser enfrentado tanto pelos profissionais da Educação, quanto pelas políticas públicas desenvolvidas no âmbito governamental. A partir da efetivação dessas políticas, entendemos que tal desafio opera-se tanto em nível teórico quanto das práticas pedagógicas relacionadas principalmente ao desejo de ensinar e de aprender, as quais englobam, de modo concreto, a relação professor - aluno. Neste ínterim, o foco problemático reside em possibilitar a aprendizagem de todas as crianças na idade de ser alfabetizada em grande parte do país.

Diante do exposto, é possível entender que essa partilha de responsabilidade se faz necessária por objetivar a comunhão de esforços no sentido de atingir o maior número de crianças alfabetizadas e letradas. Portanto, faz-se necessário que haja aprendizagem real onde as crianças possam assimilar diferentes saberes.

Se aceitarmos tal similitude, estamos considerando que o domínio da linguagem da alfabetização com letramento adquirida pelo aluno não pode ser obtida de uma só vez e sua transmissão não pode se dar no vazio, ou seja, na ausência do outro. É preciso que o conhecimento gere significado. Daí a importância de que o processo de alfabetização se dê a partir do ciclo composto por três anos com objetivos definidos para cada etapa.

De acordo com Pain (1991, p. 98), para que haja aprendizagem deve haver uma reciprocidade entre o sujeito que ensina e o sujeito que aprende, e esta relação deve abranger caminhos eficazes a fim de que a assimilação do conhecimento por parte do aluno seja construído com bases sólidas que ultrapassem a mera função de decodificar símbolos.

Na percepção de Fernández (1991, p. 52), o conhecimento é conhecimento do outro, porque o outro o possui, bem como porque é preciso conhecer o outro, quer dizer, pô-lo no lugar do professor [...] e conhecê-lo como tal. Depreende-se daí que não aprendemo de qualquer um, aprendemos daquele a quem outorgamos confiança e o direito de ensinar.

Contudo, devemos compreender que o ato de ensinar engloba os conteúdos concretos os mais variados, que devem ser considerados de suma importância no cotidiano da sala de aula onde se dá a Inter-relação entre o desejo e a prática. É através desta relação que o alfabetizando, despertará em si de uma série de estruturas cognitivas, revelando afetos e desejos os quais o impulsionará a apropriar-se do conteúdo ensinado, de modo que o torne capaz de reproduzi-lo enquanto conhecimento elaborado e, consequentemente, aplicável nos diferentes contextos sociais onde a linguagem opera.

Neste contexto, havemos de nos atentar para a "Epistemologia da Prática reflexivo" ou o conceito de "Professor Reflexivo" que surgiu através de Dewey (1959, p. 23), que propõe uma reflexão sobre a prática docente pautada em um estado de dúvida onde desencadeia a investigação com o intuito de encontrar recursos suficientes para elucidar a indagação original.

Ora, se a indagação inicial parte do desejo de entendermos o processo emblemático que vem se perpetuando a nível nacional, que é o próprio fracasso escolar a partir dos anos iniciais do Ensino Fundamental ou o não domínio da leitura, escrita e letramento, 
poderemos identificar as raizes que a sustentam que neste caso, surge direta ou indiretamente no período da alfabetização.

Neste sentido as indagações do professor sobre suas ações têm bases em suas reflexões e devem passar por um enfrentamento do problema que ocorre no cotidiano de sua própria prática enquanto professor alfabetizador. Daí urge compreender que toda ação se faz pelo desejo, ou seja: pela pulsão. Conquanto vale ressaltar que a pulsão pode dar-se numa via de mão dupla: a pulsão de Eros (vida) ou a pulsão de Tânatus (morte).

Para Rubem Alves (2004) um aspecto importantíssimo deve ser levado em al conta: que toda aprendizagem passa pelo desejo de aprender. Daí importa-nos analisar e discutir a relação ensino-aprendizagem a partir de uma visão integradora do ser humano expressa na relação vincular entre aquele que ensina e aquele que aprende, e constitu elemento inseparável e irredutível das estruturas da inteligência.

De acordo com Fernândez (1991, p. 47), para que o ser humano aprenda, quatıo elementos essenciais que formam o sujeito devem ser conhecidos: "[...] seu organismo individual herdado, seu corpo construído especularmente, sua inteligência autoconstruída internacionalmente e a arquitetura do desejo".

Ressaltamos que tais elementos devem ser características do sujeito que ensina e do sujeito que aprende sendo função da aprendizagem permitir um inter-relacionamento entre aquele que detém o saber e aquele que aprende, num processo dinâmico e dialético. Nesse processo, o professor, sendo o parceiro mais experiente da relação, deve possibilitar caminhos que conduzam o aprendiz ao conhecimento.

Não obstante, reconhecemos como Almeida (1991, p. 32), que na transmissão e apropriação do conhecimento, que ocorre numa relação sujeito a sujeito, intervêm processos conscientes e inconscientes dos pares em relação. De acordo com a autora, não há ato de ensinar-aprender sem a mediação concreta de sujeito humano, não havendo, portanto, relação ensino-aprendizagem sem que haja atuação indissociável entre inteligência, afetividade e desejo.

Vejam bem que o conhecimento constitui-se em conteúdos concretos e os mais variados possiveis que serão transmitidos na relação ensino-aprendizagem e porque năo dizer na vivencia por meio do experimento, do toque, da visão real do objeto, da percepção e assimilacão do ambiente e da realidade.

Nesta arena, professor e aluno se interagem e os materiais e métodos disponíveis à vista do aluno possibilitam a assimilação de novos e diferentes saberes. Daí, a importância do professor conhecer, identificar, perceber e utilizar os recursos metodológicos contidos no processo de letramento.

Com efeito, para (WALLON apud ALMEIDA, 1993) as emoções também podem ser causa de progresso no desenvolvimento, podem ser fonte de conhecimento, pois enquanto expressões do sujeito, as emoções precedem, acompanham e orientam as atividades de relação, sem as quais elas não teriam como capturar o mundo exterior.

PAIN (1991, p. 96), por sua vez afirma que é através desta relação que o aprendiz, usando urna série de estruturas cognitivas, e mobilizando afetos e desejo, se apropriar do conteúdo ensinado, transformando-o e sendo capaz de reproduzi-lo enquanto conhecimento elaborado.

Observemos daí, uma vez mais, a importância da atuação do professor no processo de alfabetização. Como haver transmissão de saber, se o que ensina não sabe? Não deseja? Não faz?

\section{A Efetivação do PNAIC no Brasil e em Goiás}

O PNAIC é um compromisso formal assumido pelos governos Federal, dos Estados e Municípios de assegurar que todas as crianças estejam alfabetizadas até os oito anos de idade, ao final do $3^{\circ}$ ano do Ensino Fundamental (BRASIL, 2012).

O Pacto visa oferecer formação continuada e material pedagógico aos Professores dos três primeiros anos do Ensino Fundamental, criando condições favoráveis à Alfabetização de todas as crianças até os 8 anos de idade (BRASIL, 2012, p. 1).

O Novo Pacto Nacional pela Alfabetização na Idade Certa ao ser implantado, após análise do impacto sobre a melhoria do processo de alfabetização em todo o país, apresent três eixos que são considerados ao longo do desenvolvimento do trabalho pedagógico:

Fortalecimento das estruturas estaduais e regionais de gestão do programa, o montoramento da execução e a avaliação periódica dos alunos. Formação de professores desenvolvida em parceria com as secretarias de educação e governos municipais com foco na aprendizagem do aluno do $1^{\circ}$ ao $3^{\circ}$ ano do $\mathrm{EF}$ e dos alunos com alfabetização incompleta e letramento insuficiente. Reconhecimento e valorização das escolas e dos profissionais comprometidos com a elevação dos índices de alfabetização dos estudantes (BRASIL, 2012).

Embora tenha sido implantado com a participaç̃o efetiva em todo o país, de quase totalidade dos municípios brasileiros. De acordo com o $\mathrm{MEC} / 2015$, os resultados das avaliaçoes nacionais demonstraram níveis insuficientes de alfabetizacão e letramento dos estudantes brasileiros, desafio que deve ser enfrentado por uma grande articulação entre União, sistemas de ensino e Instituições de Ensino Superior. Com o intuito de encarar este desafio com mais robustez é que foram promovidos ajustes ao desenho original do Programa (BRASIL, 2013).

É oportuno afirmar que a principal inovação no Programa é o fortalecimento das estruturas estaduais, regionais e locais de gestão de programas de apoio à alfabetização e ao letramento, com a alocação de novos perfis de coordenadores do Pacto nos estados e nas regionais de ensino, para que trabalhem junto aos coordenadores locais, já participantes do PNAIC.

De acordo com as novas propostas do MEC, as estratégias de monitoramento acompanhamento das ações do programa foram delineadas em um Plano de Gestão formulado pelo estado e aprovado no âmbito do Comitê Gestor. A proposta da formação continuada consta de um Plano de Formação, elaborado pelas IES públicas e também aprovado no âmbito do Comitê Gestor.

O Comitê Gestor Estadual Goiás, juntamente com a UNDIME (União Nacional dos Dirigentes Municipais de Educação), são os entes responsáveis pela gestão do PNAIC neste Estado.

A Secretaria de Estado da Educação de Goiás, (SEDUCE), por meio da Superintendência do Ensino Fundamental coordena o PNAIC em âmbito estadual, juntamente com o Comitê Gestor acompanham de perto as formações dos Orientadores de Estudos, realizada pela Universidade Federal de Goiás (UFG), que concluiu em 2016 a formação nicial de 40 horas dos mais de 500 orientadores da rede estadual e dos municipios. A pactir a no de 2017/2018, a Universidade Estadual de Goiás (UEG), passou a ser a Universidade responsável pelas formações. 


\section{Novas metodologias}

As formações dos 40 orientadores da rede estadual e dos mais de 450 das redes municipais foram feitas nos anos de 2013, 2014, 2015, 2016 e 2017. Os Professores conheceram novas metodologias para tornar as aulas mais atrativas aos estudantes e forma inovadoras de como trabalhar a alfabetização no campo ou com alunos com algum tipo de deficiência, entre outras situações tendo por foco o trabalho com os diferentes gêneros e tipos textuais, jogos matemáticos, além do estudo teórico sobre alfabetização e letramento, bem como o letramento matemático.

De acordo com dados do MEC/INEP (2016), em 2014 ao menos um a cada cinco estudantes no $3^{\circ}$ ano do ensino fundamental da escola pública do Brasil não atingiu nívei mínimos de alfabetização em leitura, escrita e matemática. Esse número foi obtido com base nos dados da ANA (Avaliação Nacional de Alfabetização), divulgados pelo MEC (Ministério da Educação) e analisados no contexto da Secretaria Estadual de Educação/ Superintendência do Ensino Fundamental de Goiás para fins de planejamento de açố

mais pontuais com foco nas Unidades Educacionais com baixos níveis de proficiência.

\section{Resultados da ANA}

Criada em 2013 como parte do PNAIC (Pacto Nacional pela Alfabetização na Idade Certa), pacto do MEC para alfabetizar todas as crianças até oito anos de idade, a ANA é uma avaliação externa realizada pelo Ministério da Educação (por meio do Inep) com alunos de $3^{\circ}$ ano do ensino fundamental (último ano do Ciclo de Alfabetização) de todo o país. A prova aplica testes para aferir níveis de alfabetização e letramento (BRASIL, 2014). Segundo Machado et al. (2017), o principal objetivo da ANA conforme seu Documento Básico se materializa como linha de base para a implementação das políticas previstas no Pacto, projetando a ideia de produção de novos dados estatísticos sobre a alfabetização no Brasil, pois é aplicada como uma forma de medir os efeitos do PNAIC, ou seja, de avaliar e analisar se os índices de alfabetização produzidos anteriormente ao Pacto se modificaram. Assim, por meio da ANA a estatística age sobre o ciclo de alfabetização produzindo resultados que vão impulsionar novas ações que vão operar para gerar novos resultados e consequentemente gerar novas estatísticas e produzir novos saberes.

A terceira edição da ANA foi realizada entre 14 e 25 de novembro de 2016 em escolas públicas com pelo menos dez estudantes matriculados no $3^{\circ}$ ano do Ensino Fundamental, naquele ano. Foram aplicados testes de Leitura, Escrita e Matemática. Os de Leitura tinhan 20 questões de resposta objetiva, com quatro alternativas cada. O teste de Escrita tinh três questões de resposta construída, por meio das quais o estudante teve de escrever dua palavras de estruturas silábicas distintas, com base em imagem, e produzir um pequeno texto, a partir do comando da questão. E o teste de Matemática tinha 20 questões de resposta objetiva, com quatro alternativas cada (BRASIL, 2017).

Cada área avaliada mede competências específicas e diferentes entre si. Por essa razão, as Escalas de Proficiência de Leitura, Escrita e Matemática não possuem equivalência de níveis. A articulação possível dá-se no momento da interpretação dos resultados, quando se fala em termos de proficiências insuficientes e suficientes.
Quadro 1 - Resultados Brasil SAEB/ANA 2016

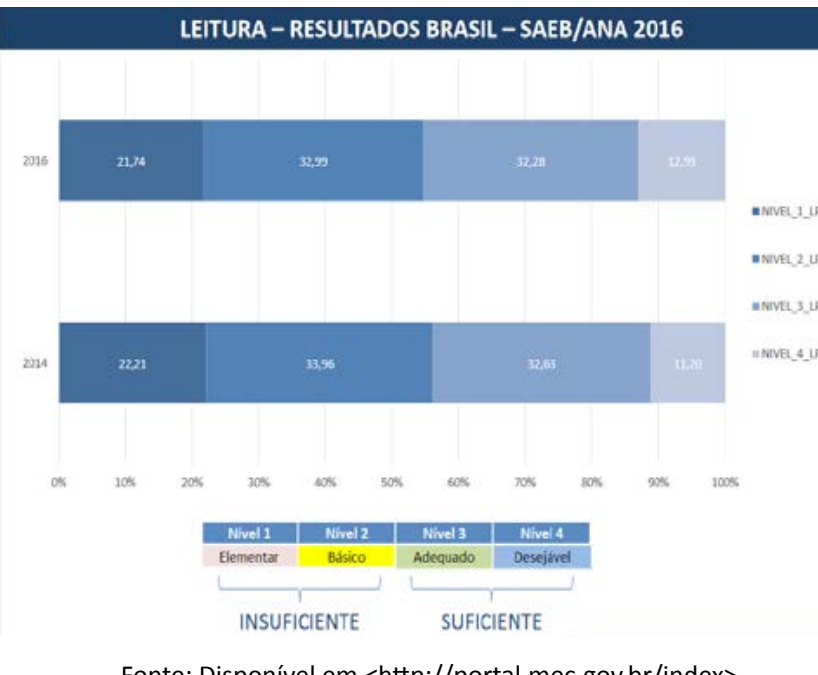

Fonte: Disponivel em <http://portal.mec.gov.br/index>.

Conforme os resultados da ANA, em nível nacional / $2014 \mathrm{o}$ índice de alunos com nivel insuficiente em leitura era de 56,17\%, agora está em 54,73\%, o que indica a estagnação na melhoria das taxas.

De acordo com dados do INEP/2016, comparados aos resultados de 2014, em relação ao domínio da leitura, percebe-se uma melhora no que se conceitua como desejável - proficiência Nível 4, mantendo-se basicamente empatado no que tange ao nível de proficiência adequado Nível 3. O mesmo ocorre no quesito básico, havendo uma ligeira diminuição em 2016 quanto ao Nível 1.

\section{Quadro 2 - Leitura Resultados Estados SAEB/ANA 2016}

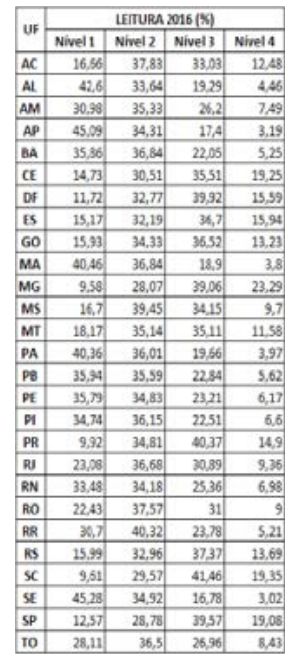

Fonte: Dispo

A divulgação de dados relativos ao desempenho das crianças, no que se refere ao domínio das habilidades básicas nas áreas de leitura, escrita e conhecimentos matemáticos, aponta para a expectativa de se responder a problemática quanto aos baixos desempenhos dos alunos nesta fase escolar. Por meio de uma análise sobre o processo pedagógico, cada Unidade Escolar deve incidir sobre o que o professor trabalha em sala de aula e sobre o que a criança manifesta saber.

Para Leal (2012), cabe ao professor, no que se refere à avaliação dos alunos: a iden-

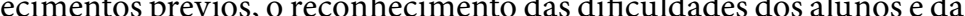


aprendizagens que acumulam e a definição de encaminhamentos relativos à progressão da criança de um ano para outro.

A partir daí decorrem tarefas comumente atribuídas ao escopo profissional do professor: "[...] o planejamento da ação pedagógica e a organização das informações sobre as crianças e dos materiais de uso são os pilares básicos para que as intenções docentes sejam concretizadas e todas as crianças aprendam o que lhes é de direito" (LEAL, 2012, p. 19). Reiteramos, assim, a importância da formação continuada de professores alfabetizadores com base na analise dos resultados de cada escola.

\section{Quadro 3 - Escrita Resultados Estados SAEB/ANA 201}

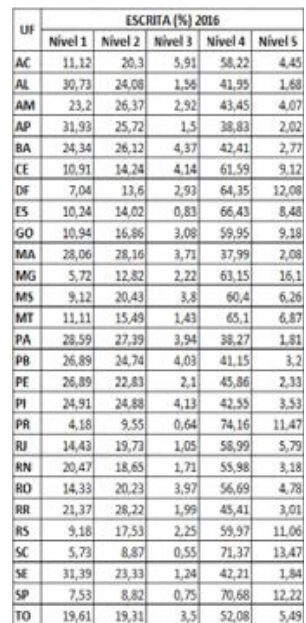

Fonte: Disponivel em <http://portalmec govbr/inder

A partir das análises dos dados no geral e em particular (por unidade educacional), faz-se necessário foco dos profissionais que atuam nas Unidades Escolares a elaboração de planejamento, acompanhamento das aprendizagens, elaboração de atividades que promovam o desenvolvimento das crianças objetivando superar as dificuldades apresentadas e, consequente a inserção de todos os alunos no universo alfabetizado/letrado.

Os objetivos da avaliação/ANA bem como a análise dos dados devem configurar como componente do trabalho pedagógico do professor (como ação do PNAIC), tendo como meta principal a aprendizagem infantil. Concebidos dessa forma, os instrumentos não devem restringir a experiência da aprendizagem a um conjunto de "[...] competências, indicadores, gráficos e dados, ou seja, fragmentos quantificáveis que em muito se distanciam das relações que cada sujeito efetivamente estabelece com a cultura escrita" (ESTEBAN, 2012, p. 578).
Quadro 4 - Matemática :Resultados SAEB/ANA 2016

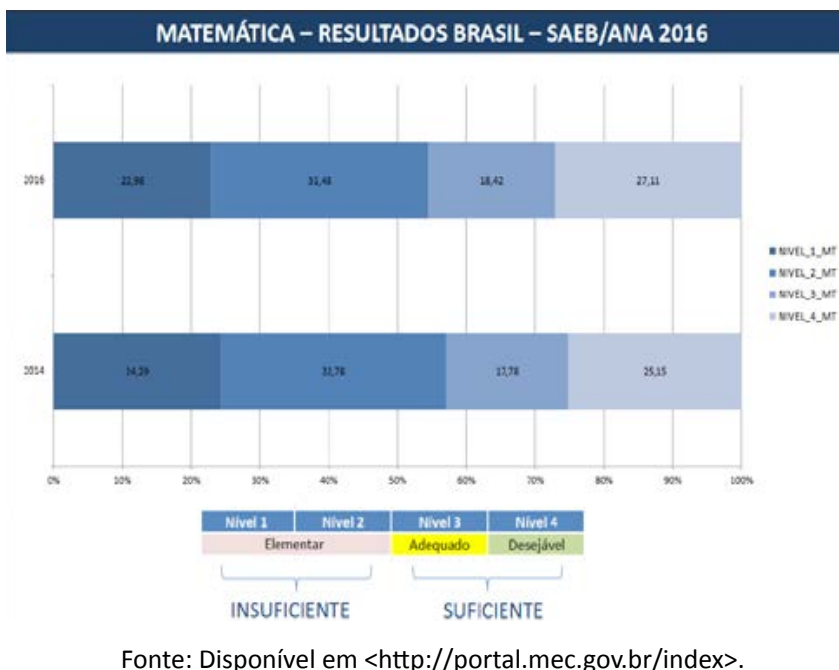

Quadro 5 - Matemática: Resultados Estados SAEB/ANA 2016

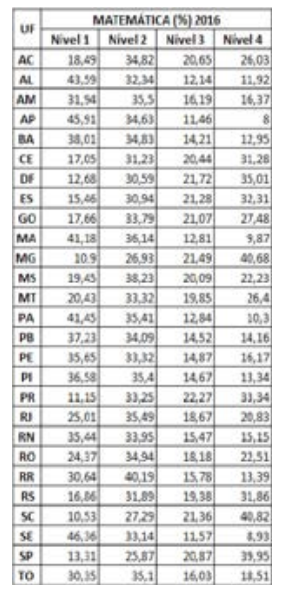

Fonte: Disponivel em <http://portal.mec.gov.br/index>

Inserir práticas de leitura e escrita em aulas de matemática se torna indispensáve uma vez que o termo alfabetização matemática é definido como uma ação inicial da criança de ler e escrever matemática, o que a leva a compreender e interpretar seus conteúdos básicos sabendo expressar-se por meio de sua linguagem característica (SOUZA, 2010).

Na perspectiva do Ensino da matemática, o material do PNAIC instrui os professores a explorarem problemas que investigam se o aluno aprendeu ou não um determinado conteúdo. Aprender matemática está aliado ao processo de desenvolvimento de múltiplas linguagens, e para isso é necessário que professores convidem os alunos a participarem das aulas e argumentarem quando são apresentadas questões que sugerem uma investigação. Para tanto, o aluno tem que pensar e refletir para realizar uma determinada resposta, sobre um determinado problema. Desenvolver esse processo com a aplicaça de jogos e A soma das avaliações aplicadas em todos os municípios de Goiás com relação aos conhecimentos em matemática, apontaram que 51,45\% apresentaram desempenho abaixo do adequado, enquanto $48,97 \%$ com nível suficiente. Norte e Nordeste registraram 70,64\% 69,46\% dos estudantes com conhecimentos em matemática insuficientes. 


\section{Resultados do Ideb 2015}

O Ideb é um indicador geral da educação nas redes privada e pública, uma espécie de nota. Para chegar ao índice, o MEC calcula a relação entre rendimento escolar (taxas de aprovação, reprovação e abandono) e desempenho em português e matemática na Prova Brasil, aplicada para crianças do $5^{\mathrm{o}}$ e $9^{\circ}$ ano do fundamental e do $3^{\circ}$ ano do ensino médio.

O índice é divulgado a cada dois anos e tem metas projetadas até 2021, quando a expectativa para os anos iniciais da rede estadual é de uma nota 6,0. Assim, para que o Ideb de uma escola ou rede cresça é preciso que o aluno aprenda, não repita o ano e frequente as aulas.

De acordo com dados do MEC - INEP, a nota geral do Ideb no país foi superada no ciclo inicial do ensino fundamental (de $1^{\circ}$ ao $5^{\circ}$ ano), mas ficou abaixo da meta projetad no ciclo final Conforme os resultados apresentados, o Ensino Fundamental anos iniciai $\left(1^{\circ}\right.$ ao $5^{\circ}$ ano) foi a etapa de destaque. A meta prevista era de 5,2 e o resultado alcançado fo de 5,5. Só nesta etapa são 1179 mil escolas e 15,5 milhões de alunos considerando a rede pública e a rede privada. $82,5 \%$ dos alunos desta etapa pertencem à rede pública municipal.

Os resultados dos anos iniciais do Ensino Fundamental avançaram, embora muitos alunos do país ainda apresentem um nível de proficiência muito abaixo do desejável. O Ideb da rede pública em 2015 foi de 5,3 e o Ideb geral do país foi de 5,5.

\section{Quadro 6 - Ideb Observado e Metas}

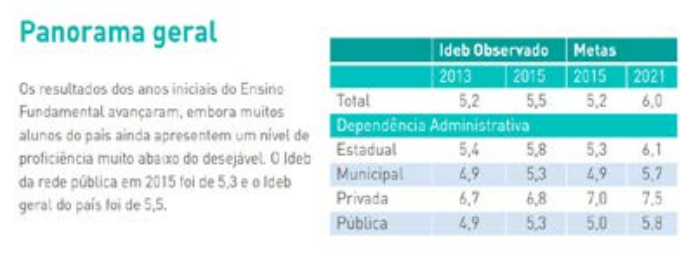

Fonte: Disponivel em: <http://www.fundacaolemann.org.br/>

Apesar do patamar ainda não representar o indicador desejável, avançamos consideravelmente na direção da meta de 6,0 para 2021. O indicador que era $4,2 \mathrm{em} 2007$ já é de 5,5 .

Dados divulgados pelo Ministério da Educação (MEC/2016) mostram que Goias superou a meta estipulada para o Índice de Desenvolvimento da Educação Básica (Ideb) 2015 no ensino fundamental.

Segundo o levantamento, nos anos iniciais do ensino fundamental - da $1^{\mathrm{a}}$ a $5^{\mathrm{a}}$ série - Goiás alcançou nota de 5,8, indo além do estipulado, que era um índice de 5,4. Neste quesito, o estado ficou atrás de São Paulo, Santa Catarina, Minas Gerais, Parană, Distrito Federal e Ceará. Somente Tocantins não teve evolução.

Já nos anos finais, que compreendem o período entre o $6^{\circ}$ e o $9^{\circ}$ anos, o desempenho também foi acima do estipulado. Com 4,9, ultrapassou a meta de 4,7. A sua frente, ficaram apenas Santa Catarina e São Paulo. Apesar disso, além de Goiás, Pernambuco, Amazonas, Mato Grosso e Ceará cumpriram o Ideb.

Em relação ao Ensino Fundamental também da rede estadual, Goiás alcançou nota 6,0 nos anos iniciais $\left(1^{\mathbf{0}}\right.$ ao $5^{-}$ano), ficando atrás de Minas Gerais e Paraná, ambos con 6,2. Já nos anos finais ( $6^{-}$ao $9^{\circ}$ ano), Goiás atingiu 4,5 , sendo superado por Minas Gerais, com 4,7. Consideracões Finais A frequência com que se depara com a temática do processo de alfabetização e letramento dentro do universo escolar, fica evidente que a formação continuada do professor alfabetizador é importante, posto que as propostas apresentadas pelo PNAIC através do MEC confere a estes profissionais a posição de atores principai em sua própria formação.
Assim, este professor deve apropriar-se de diferentes estudos sobre o tema, envolverse de modo desejoso e reflexivo dentro do processo que engloba o ato de alfabetizar letrando bem como estudar outros autores que tratam do assunto e trazem contribuiçoes significativas que fortalecem o planejamento de atividades desafiadoras dentro da sala de aula, lembrando que o processo de letramento é um elemento - janela que possibilita ao aluno uma visão extra- conteúdo.

Leal (2015) entende que as ações propostas nos textos dos cadernos do PNAIC confluem para o princípio segundo o qual "[...] a alfabetização na perspectiva do letramento é um processo em que, ao mesmo tempo, as crianças possam aprender como é o funcionamento do sistema de escrita alfabética, de modo articulado e simultâneo às aprendizagens relativas aos usos sociais da escrita e da oralidade" (LEAL, 2015, p. 34).

Embora os programas e ações propostas pelo MEC tenham proporcionado avanços, é necessário garantir a continuidade destas políticas e o acompanhamento por parte das Secretarias de Educação dos Estados e Municípios. Uma análise dos resultados por Unidade Escolar, poderá proporcionar condições para amenizar as dificuldades as crianças e, consequentemente as carências no sistema educacional brasileiro, promovendo na medida do possível, a democratização da educação básica e de qualidade social para todos, contrariando a conceituação de Freud sobre a impossibilidade da Educação.

Sabemos que todo esforço realizado até aqui não esgota a possibilidade de ouvirmos todos os ecos que retumbam dos diversos contextos educacionais do país que veem a preocupação em estar justificando de modo coerente e eficaz, a ampliação do Ensino Fundamental para nove anos, bem como a continuidade do Programa de Formação PNAIC, suscitando análises e reflexões que estimulem a problematização do tema "Alfabetizar na Idade Certa" para que possamos trilhar novos rumos, que promovam de modo exitoso o desenvolvimento sócio cognitivo de nossas crianças.

\section{Referências}

ALBUQUERQUE, Eliana Borges Correia. Conceituando alfabetização e letramento. In: SANTOS, Camila Ferraz. Alfabetizacão e Letramento: conceitos e relacôes. Belo Horizonte: Autêntica, 2005. ALMEIDA, Sandra Francesca Conte de. O lugar da afetividade e do desejo na relação ensinar aprender. Revista Temas em Psicologia, Ribeirão Preto, v. 1, n. 1, abr. 1993.

ALVES, Rubem. O Desejo de Ensinar e a Arte de Aprender. Campinas: Fundação Educar DPaschoal 2004.

ARELARO, Lisete Regina Gomes. FUNDEF: Uma Avaliação Preliminar dos Dez Anos de sua Implantação. Caxambu, MG: ANPED, 2007. Disponivel em: <http://anped.org.br/sites/default/ files/gt05-3866-int.pdf>. Acesso em: 6 set. 2017.

ARELARO, Lisete Regina Gomes; JACOMINI, Márcia Aparecida; KLEIN, Sylvie. O Ensino Fundamental de Nove Anos e o Direito à Educação. Revista Educ. Pesquisa, São Paulo, v. 37, n. 1, jan./abr. 2011. Disponivel em: <http://dx.doi.org/10.1590//1517-97022011000100003> Acesso em: 17 set. 2016 BRASIL. Ministério da Educação. Secretaria de Educação Básica. Diretoria de Apoio à Gestão Educacional. Pacto Nacional pela Alfabetização na Idade Certa. Ano 1, Unidade 8. Organização do Trabalho Docente para Promoção da Aprendizagem. Brasília, DF: MEC, 2012.

Ministério da Educação. Secretaria de Educação Básica. Ensino Fundamental de Nove Anos. . Relatório de Observação no. 5: As Desigualdades na Escolarização no Brasil. Brasília, DF: Conselho de Desenvolvimento Econômico e Social, 2014. p. 61-62.

Instituto Nacional de Estudos e Pesquisas Educacionais Anísio Teixeira. Resultados do PISA. Brasilia, DF: MEC/INEP, 2009. Disponivel em: <http://portalinep.gov.br/internacionalnovo-pisaresultados>. Acesso em: maio 2017. 
. Secretaria de Educação Básica. Instituto Nacional de Estudos e pesquisas Educacionais Anísio Teixeira. Avaliação nacional da alfabetização. Brasília, DF: MEC/INEP, 2013. Disponível em: <http://portal.inep.gov.br/web/saeb/Ana >. Acesso em: maio 2017.

. Ministério da Educação. Conselho Nacional de Educação. Resolução CNE/CEB n. 7/2010. Fixa Diretrizes Curriculares Nacionais para o Ensino Fundamental de 9 (nove) anos. Disponível em: <www.mec.gov.br/cne>. Acesso em: maio 2017.

. INEP. Resultados da ANA 2016 por estados e municípios estão disponíveis no Painel Educacional do INEP. Brasília, DF, out. 2017. Disponível em: <http://portal.mec.gov.br/index.php?option $=$ com_docman\&view $=$ download\&alias $=2464$-parecer-ceb-22-2009\&Itemid=30192 $>$. Acesso em: nov. 2017.

. Ministério da Educação. Parecer CNE/CEB n. 22/2009. Disponível em: <http://portal.mec. gov.br/docman/janeiro-2010-pdf/2464-parecer-ceb-22-2009>. Acesso em: nov. 2017.

DEWEY, John. Como pensamos como se relaciona o pensamento reflexivo com o processo educativo: uma reexposição. Tradução Haydée Camargo Campos. 4. ed. São Paulo: Nacional, 1979a. 292 p. (Série Atualidades pedagógicas, v. 2).

. Como pensamos. 3. ed. São Paulo: Editora Nacional, 1959.

FERNÁNDEZ, A. A inteligência aprisionada. Porto Alegre: Artes Médicas, 1991. 261 p.

FERREIRO, Emilia; Teberosk, Ana. A Psicogênese da Língua Escrita. Porto Alegre: Artes Médicas, 1985. $284 \mathrm{p}$.

FREUD, S. Análise terminável e interminável. v. 23. Tradução D. Marcondes et al. Rio de Janeiro: Imago, 1937. (Série Edição Standard Brasileira das Obras Psicológicas Completas, v. XVI).

FURGHESTTI, M. L. S.; GRECO, M. T. C.; CARDOSO, R. C. F. Ensino Fundamental de Nove Anos: os Impactos das Políticas Públicas para a Alfabetização com Letramento. Dissertação (Mestrado em Educação)-Universidade do Sul de Santa Catarina (UNISUL), 2012.

JORNAL DO BRASIL. Letramento versus alfabetização. "Letrar é mais que Alfabetizar": Entrevista com Magda Becker Soares. 26 nov. 2000. Disponível em: <http://intervox.nce.ufrj.br/ edpaes/ magda.htm>. Acesso em: maio 2016 .

LEAL, T. F. Currículo no Pacto Nacional pela Alfabetização na Idade Certa: os direitos de aprendizagem em discussão. Educação em Foco, Juiz de Fora, Edição Especial, p. 23-44, fev. 2015.

MACHADO, R. I.; LOCKMANN, K. Pacto Nacional pela Alfabetização na Idade Certa: ciclo de alfabetização. Avaliação nacional da alfabetização - uma engrenagem biopolítica circular a serviço do neoliberalismo. Rio Grande, RS: FURG, 2017.

PAIN, Sara. A Função da Ignorância e a Gênese do Conhecimento. v. 2. Porto Alegre: Artes Médicas, 1991.

SOARES, Magda. As muitas facetas da alfabetização. In: Alfabetização e Letramento. São Paulo: Contextos, 2003.

. Linguagem e escola: uma perspectiva social. 7. ed. São Paulo: Ática, 1989.

. Alfabetização e Letramento. 6. ed. São Paulo: Contexto, 2011. 123 p. 